\title{
MODAL VERBS TO EXPRESS CONFIDENCE / UNCERTAINTY
}

\author{
Liudmyla Nizhnik \\ Postgraduate Student, Chernivtsi National University, Ukraine \\ e-mail: liudanizhnik@gmail.com,orcid.org/0000-0003-1411-0561
}

\author{
Andrii Galaidin \\ Ph.D. student, Polonia University in Czestochowa, Interdisciplinary Faculty, Poland \\ e-mail: a.galaidin@ap.edu.pl,orcid.org/0000-0002-5236-1495
}

\section{Summary}

The article deals with the concepts of modality and the way it influences utterances in a fictional discourse. The confidence / uncertainty of the utterances with epistemic modal verbs (must, have to / have got to, might, may, could, should, ought to, would, will) was analyzed and ranked on the probability scale of Renooij S. and Witteman C. It was found that must, have to, modified with epistemic words will and would and hypothetic will belong to "probable" (85\%) part of the scale, should, ought to, and hypothetic would belong to "fifty-fifty" (50\%) part of the scale, might, may, could belong to "uncertain" (25\%) part of the scale, might not, may not, could not, would not, should not belong to "improbable" (15\%) part of the scale, can't, will not belong to "impossible" $(0 \%)$ part of the scale. The article also analyzed modality strength and degree of modal verbs and direction of uncertainty of utterances with modal verbs. An important point discovered in the research is that other epistemic words that co-occur with epistemic modal verbs influence their direction of uncertainty, strength and degree of modality. The influence of epistemic words on modal verbs with a strong deontic component and futurality component was studied. The article also studies the structural composition of utterances with different modal verbs. It's discovered that should, ought to, could are often followed by existential propositions and may, could are followed by contradictory propositions.

Keywords: modality, epistemic words, probability scale, confidence, uncertainty.

DOI: https://doi.org/10.23856/4007

\section{Introduction}

Today, a great importance is paid to the study of a probability scale. This scale is used to describe the strength of faith in terms of accuracy or quality of prediction, judgment, or choice, and is "described through a continuum ranging from complete certainty to complete doubt or impossibility" (Wesson 2009: 151). Different scholars (Berry N., Wesson C., Teigen K., Renooij S., and Witteman C.) place epistemic words and expressions differently on a probability scale. Thus, Berry N. (Berry, 1960) says that words of confidence are placed along a continuum with such intermediate terms as suppose, think, sure, certain, positive, where each subsequent term conveys a higher degree of confidence. Wesson C. (Wesson, 2009) offers a seven-point probability scale, where a greater confidence is conveyed with every higher point. Teigen K. (Teigen, 1995:34) says that words of probability can be placed on a scale from 0 to 1 , where words denoting faith are close to 1 , and words denoting doubt - close to 0 . To the middle of the probability scale $\mathrm{p}=0.50$, he includes such words, as perhaps, maybe, and notes that they are used in case we do not want to commit to what has been said. Renooij $\mathrm{S}$. and Witteman C. (Renooij, Witteman, 1999: 191), analyzing medical oral discourse, propose a 
probability scale that has such parts as "certain" (100\%), "probable" (85\%), "expected" (75\%), "fifty-fifty" (50\%), "uncertain" (25\%), "improbable" (15\%) and "impossible" (0\%). There is a digital counterpart (1 to 100) opposite each scale mark.

The relevance of this study is that so far no comprehensive analysis of epistemic modal verbs to denote confidence / uncertainty in English fictional written discourse has been made. Confidence / uncertainty are considered in relation to probability. Typically, scholars do not distinguish between "confidence", which relates primarily to the state of mind, from "probability", which is used to describe external events, plausibility or reliability, and place the terms confidence and probability along the same scale. There are an internal uncertainty, which is a combination of cognitive state and emotions (belief, doubt) and an external uncertainty, which includes factors of chance and potentiality (probable, possible) (Wesson, 2009).

The aim of the study is to analyze epistemic modal verbs in English fictional discourse and place them on the probability scale of Renooij S. and Witteman C. (Renooij, Witteman, 1999). The tasks of the article are: to find out the strength and degree of modality of epistemic modal verbs (Huddleston, Pullum: 2002); to identify the influence of other epistemic words on the direction of uncertainty (Teigen: 1995) of expressions with epistemic modal verbs. The material of the research is the English fiction discourse of the end of the $\mathrm{XX}$ - the beginning of the XXI century. Research methods include contextual and distributional analysis.

\section{Modal verbs with high degree of confidence}

The main feature of the epistemic must is the expression of the speaker's confidence in the truth of what he says on the basis of the logical process of deduction from the assumption that borders on certainty that is analyzed in the following examples. In these examples, the characters draw conclusions based on what usually happens and is the norm. That is, a particular case is not a deviation from the norm, so it is acceptable to believe in it and to be confident in it:

(1) He must be a bit drunk too, thought Madeline. He wouldn't normally refer to Bonnie as his "wife" in front of her (Moriarty, 2014: 339).

(2) "What's that?" she said, pointing to my cheek.

"What do you mean?"

"I mean, Nick, what is wrong with your face? There's a giant pink ..." She leaned in closer, grabbed my chin. "It's like a bite mark."

"It must be hives. I get hives when I'm stressed" (Flynn, 2012: 246).

Often, the epistemic must, which expresses the speaker's faith in the event, is modified with accompanying modal epistemic phrases, such as I guess, I suppose, which soften the confidence that conveys must. This can be seen in the following examples:

(3) "First I thought, Oh, well, I guess they must be enjoying themselves too much to recall it's my lunchtime" (Tyler, 2004: 72).

(4) "Do people sign cassettes? I suppose they must do" (Hornby, 1995: 190).

Epistemic must helps to make judgments about the event at the moment of speaking. Epistemic must in combination with the verb form of the infinitive or continuous and perfect aspect is used to denote an assumption concerning the present or past tense, as in the following examples:

(5) He must be feeling horrible (Hawkins, 2015: 160).

(6) "That could be a good sign too. It proves he misses his mother, which means she must have behaved like a mother. Evidently they'd formed an attachment" (Tyler, 2004: 153). 
Epistemic mustn't is not found in discourse, as mustn't has a deontic meaning. Exceptions are tag questions. In tag and general questions with an epistemic must, the speaker seeks confirmation of what he is talking about, thus such utterances convey uncertainty:

(7) "But if she was having an affair, she must have been unhappy, mustn't she?" (Hawkins, 2015: 128)

(8) Harry poured the wine then sniffed his glass, sipped it, rolled it around in his mouth then smacked his lips. "Great bouquet. Full rich body. Hearty yet smooth. A magnificent wine. Must be at least a week old, right?" (Selby, 1999: 38)

Epistemic have to conveys a high level of probability, but is much less common in discourse than must. In the following example, have got to expresses affective epistemic modality:

(9) "You're joking," I said softly, fondling a pair of Dior sunglasses he'd apparently thrown in as an afterthought. "You've got to be kidding" (Weisberger, 2003: 132).

Some linguists (Collins P., Huddleston, Pullum, Coates J.) single out epistemic will for expression of confidence, considering will (and ' $l l$ ) as a bearer of tense and modality, but others (Wekker H., Palmer K.) think that this verb is only a bearer of tense. Thus, Coates J. argues that epistemic will is similar to epistemic must in expressing the speaker's confidence in the uttered proposition. Palmer F. (Palmer, 1990: 163) dwells on the distinction between judgment and factual statement, according to which the sentence in the future tense does not convey an epistemic judgment, but only states the factual statement. In this study, we believe that will indicates a temporal affiliation, and utterances with will denote the speaker's prediction and convey subjective judgment only when they contain other markers of epistemic modality or when will is used hypothetically.

In the following examples, will and would state the facts in the future:

(10) My stylist will dictate my look for the opening ceremonies tonight anyway (Collins, 2008: 18).

(11) Bradley had told him the ride would be at least an hour and a half, with two stops for roadblocks, perhaps more (King, 2014: 72).

In the following examples, prediction is subjective, as evidenced by other modality markers - perhaps, I think, so will and would are epistemic here:

(12) Perhaps he would be a goon all his life. Perhaps he would learn (King, 2014: 152).

(13) "I think the cops will laugh us out of the station if we say right now that Amy framed you" (Flynn, 2012: 262).

Will in combination with the perfect construction does not convey the meaning of the assumption in the past tense, as with must, but is a temporal form of Future Perfect and states the fact that will happen until a certain point in the future. Will in combination with the continuous aspect is a temporal form of Future Continuous and states the fact that will happen at some point in the future.

Hypothetical will has an epistemic meaning and expresses a high probability that some event will occur. In example [14], epistemic will is equal to epistemic must:

(14) "And you can make a decision about it just like that, can you? In cold blood, bang bang, if I do that, then this will happen? I'm not sure that it works like that."

"But it does, you see. Just because it's a relationship, and it's based on soppy stuff, it doesn't mean you can't make intellectual decisions about it" (Hornby, 1995: 214).

Hypothetical would usually expresses an epistemic meaning because it indicates the probability of what is being said, but this probability is less than that of will:

(15) Everything would just sort itself out if I just stopped worrying so much (Weisberger, 2003: 178). 
Weak use of the hypothetical would includes such features as tentativeness, uncertainty, politeness. In [16], the main character wants to break up with the heroine, so he says it carefully giving arguments for such a decision. He wants to be polite and tactful at such a difficult moment. In the following case, the epistemic would is less sure and straightforward than will:

(16) "What? What are you saying? You want to break up?" I asked, realizing much too late that he was very, very serious.

"No, not at all. Not break up, just take a break. I think it would help both of us if we reevaluate what we've got going here. You sure don't seem happy with me lately, and I can't say I'm thrilled with you. Maybe a little time away would be good for both of us" (Weisberger, 2003: 218).

\section{Modal verbs with a high degree of uncertainty}

Epistemic may has a meaning different from must and indicates "the speaker's lack of confidence in the utterance" (Coates, 1983: 131). With this modal verb, the speaker expresses an assumption, but it is much weaker than the assumption with must. The speaker uses may to make assumptions of different content - both true and false, while must is used to express only those assumptions that in his opinion are true. Using epistemic may, the speaker indicates his uncertainty as to what will happen:

(17) "The doctor just called and said that Lily is showing signs that indicate she may come out of it soon. Isn't that great? I thought you'd want to know" (Weisberger, 2003: 257).

From example [18] we can conclude that the speaker is not sure of the judgment. The speaker also expresses a weak commitment to the content of what he is talking about. Thus, epistemic may is paraphrased as "It is probable that ..." or it is equivalent to epistemic markers perhaps, probably, and maybe.

(18) She put her hands on my shoulders, holding me in place, her fingers flexing sporadically to emphasize her words. "We may already be too late. I saw him going to the Volturi... and asking to die" (Meyer, 2005: 211).

In utterances, may is often used in the first part, followed by but and the second part of the utterance. This structure of the statement indicates the falsity of the assumption expressed by may:

(19) I may be smaller naturally, but overall my family's resourcefulness has given me an edge in that area. I stand straight, and while I'm thin, I'm strong (Hornby, 1995: 31).

If the utterance with may is modified by epistemic phrases of thinking (e.g. I think, I guess), then the confidence of the utterance with may increases:

(20) "I really, really need more information. About your-"

"Don't say friendship." I heard an angry grin in her voice.

"No. I wouldn't. I just want to hear your side. I am not calling because I think you've got anything - anything - to do with my wife, her situation, currently. But I would really like to hear what happened. The truth. Because I think you may be able to shed light on a ... pattern of behavior of Amy's" (Flynn, 2012: 281).

In terms of tense, epistemic may is combined with the perfect form of the next verb (may have V3) and conveys the speaker's judgment about the possibility of a past event, as in [21]. Epistemic may is combined with the continuous aspect of the next verb (may be Ving) to express the possibility of an action occurring at the moment of speaking, as in [22], or for a temporal reference to the future [23]. 
(21) So I may have gone a bit mad. I do know that framing your husband for your murder is beyond the pale of what an average woman might do. But it's so very necessary. Nick must be taught a lesson. He's never been taught a lesson! (Flynn, 2012: 229)

(22) Caesar Flickerman gives me a warm hug when I come in.

"Congratulations, Katniss. How are you faring?"

"Fine. Nervous about the interview," I say.

"Don't be. We're going to have a fabulous time," he says, giving my cheek a reassuring pat.

"I'm not good at talking about myself," I say.

"Nothing you say will be wrong," he says.

"And I think, Oh, Caesar, if only that were true. But actually, President Snow may be arranging some sort of accident for me as we speak" (Collins, 2008: 120).

(23) When we reach the jungle, we peer into it, trying to decipher what may be waiting inside. "Well, it must be monkey hour. And I don't see any of them in there," says Peeta. "I'm going to try to tap a tree" (Collins, 2008: 110).

May and may not used at the same time indicate that the speaker is indecisive or has no commitments to the utterance, and also expresses a lack of responsibility for the content of the utterance:

(24) I was in disbelief that I'd just explained my dreary life to this bizarre, beautiful boy who may or may not despise me (Meyer, 2005: 27).

May not is used to express the assumption that something is unlikely. May not denies the proposition, not the modality:

(25) Lily was peering at me with an encouraging look, one that screamed, He's beautiful, Andy! Beautiful! I may not know who the hell he is, but he wants you so pull yourself together and tell him how much you love Au Bar! (Weisberger, 2003: 176)

May not denies the proposition in the present and past tense:

(26) "Can't you stop for one second to think about the fact that I may not want to go either, but I have no choice?"

"No choice? You have nothing but choices! Andy, this job isn't just a job anymore, in case you've failed to notice - it's taken over your entire life!" he yelled back, the redness in his face expanding to his neck and ears [DWP, 217].

(27) 'A thirty-five-year-old man is being questioned under caution at Witney police station regarding the disappearance of Megan Hipwell, missing from her home since Saturday evening.' That's Scott, I'm sure of it. I can only hope that he read my email before they picked him up, because questioning under caution is serious - it means they think he did it. Although, of course, it is yet to be defined. It may not have happened at all. Megan might be fine (Hawkins, 2015: 74).

Epistemic may in questions is rare. Maybe is seen in questions much more often. Maybe is an adverb in modern English, but it was formed in the late Middle English period from may be (that). The following questions with maybe occur in the discourse:

(28) She didn't feel the same like she did when she first started taking the pills. It was like they took something out of them. Maybe they made a mistake and gave her the wrong pills? Maybe she should get stronger ones? She called the doctor's office and talked with the nurse and asked two, three, how many times, if she was sure she didn't give her the wrong pills? (Selby, 1999: 88)

Epistemic might historically stems from the "unrealistic" use of may, but now might is considered real rather than conditional. Collins P. notes that may and might differ in the degree of formality, not the degree of confidence (Collins, 2009: 112). Epistemic might occurs more 
frequently in speech than in writing, while epistemic may occurs much more frequently in writing than in speech (Collins, 2009: 112). Might expresses the probability and assumption of the situation:

(29) I just know that I have to start talking. If I don't do it now, I might never have the courage to say the words out loud, I might lose them altogether, they might stick in my throat and choke me in my sleep (Hawkins, 2015: 135).

Might repeated in parallel syntactic constructions with different propositional content of utterances, indicates ignorance, confusion, lack of certainty, uncertainty:

(30) "But in your opinion, would I definitely go?"

"How am I supposed to know that? You might get run over by a bus, or go blind, or anything. You might go off the idea. You might be broke. You might just get sick of people telling you you've really got to go" (Hornby, 1995: 99).

However, might in repetitive utterances with the same propositional content makes the assumption more likely:

(31) Here's her last entry: This man might kill me. This man might kill me, in her own words (Flynn, 2012: 333).

A stylistic device repetition is used in [30] and [31]. Repetition is expressive, emphasizes the repeated meaning and emotionally elevates it. Example [30] considers repetition at the distance - deliberate repetition of a speech form that does not come into direct contact with the repeated form, which makes this language form more expressive in the discursive flow.

Might makes an assumption in the judgment. On the probability scale, it takes a certain direction in case when it is modified by epistemic phrases. Thus, in [32] the epistemic phrase we hope directs the assumption with might to a greater probability:

(32) "Do you think it will simply go away?" Horton asked Coal.

"It might. For obvious reasons, we hope so" (Grisham, 1992: 323).

Might is used to describe the probable situation in the present [33], past [34] and future tense [35]:

(33) "Now - I think he might be dead."

"Why do you think that?"

"I don't know. He just ... he feels dead to me" (Hawkins, 2015: 172).

(34) He isn't seeing Rachel behind my back! The idea is ridiculous. She might have been attractive once - she was quite striking when he met her, I've seen pictures: all huge dark eyes and generous curves - but now she's just run to

Fat (Hawkins, 2015: 192).

(35) "I think it might be going to snow," Michael said as he stepped inside.

"Yes, that's what they're saying, all right" (Tyler, 2004: 59).

Might not expresses a negative probability and denies the proposition referred to in the utterance:

(36) I might not particularly love fashion, but I'd sure rather do something "fun" all day long than get sucked into a more boring job (Weisberger, 2003: 14).

Might in questions puts into question the assumption:

(37) I write down a list of most likely possible explanations for the disappearance of Megan Hipwell...I think the first possibility is most likely, and four is a strong contender, too, because Megan is an independent, wilful woman, I'm sure of it. And if she were having an affair, she might need to get away to clear her head, mightn't she? Five does not seem especially likely, since murder by a stranger isn't all that common (Hawkins, 2015: 55). 
Epistemic can is mostly used in negative and interrogative sentences and its use "fills the epistemic gap for the must not, which in its negative form is devoid of epistemic semantics" (Coates, 1983: 19). Can't indicates a lack of probability bordering on confidence:

(38) "I expect you to attend the party tonight to greet the guests. That's all."

I looked to Emily, who looked absolutely baffled, her crinkled forehead making her appear as dumbfounded as I felt. "Did I hear her correctly?" I whispered to Emily, who could do nothing but nod and motion for me to come to her side of the suite.

"She can 't be serious. It's four o'clock on Friday. The party starts at seven. It's black tie, for chrissake-there is no way on earth she expects me to go" (Weisberger, 2003: 192).

Can't is often found in combination with epistemic words think, believe, be sure, be certain. In our opinion, these epistemic words give can't more epistemic weight and expressiveness:

(39) Scott, presumably. I can't believe he would have hurt her. I know that he wouldn't. I've seen them together; I know what they're like together (Hawkins, 2015: 57).

In example [40], can't is used with epistemic think, which means "to have an opinion" and is a certain cognitive state. This think gives can't an epistemic weight. The character expresses disbelief in what he has heard and provides an argument with can't, which would indicate the absence of probability in a certain unfolding of events:

(40) "It's a petition to have Ziggy suspended from the school," said Samantha with an apologetic grimace, as if she'd stepped on Madeline's toe. as to sign it!"

"What? That's ridiculous! Renata can't possibly think people would be so small-minded

"It wasn't Renata. I think it was Harper who started it," said Samantha (Moriarty, 2014: 212).

And in [41] think means "to think, to be in an active process" and is an action, it is not epistemic, so can't retain its original deontic meaning:

(41) When did this house become so bloody small? When did my life become so boring? Is this really what I wanted? I can't remember. All I know is that a few months ago I was feeling better, and now I can 't think and I can't sleep and I can't draw and the urge to run is becoming overwhelming (Hawkins, 2015: 133).

Epistemic adverbs, such as possibly, likely, also give can an epistemic weight and indicate that can is used epistemically. In the given example, can without an epistemic adverb would convey only a deontic meaning:

(42) "You two, you're fucking addicted to each other. You are literally going to be a nuclear family, you do know that? You will explode. You will fucking detonate. You really think you can possibly do this for, what, the next eighteen years? You don't think she'll kill you?" (Flynn, 2012: 400)

Epistemic can in questions refers to the probability of an event, not the ability to perform an action:

(43) "Can this call be traced?"

"Possibly, I guess" (Grisham, 1992: 55).

Epistemic could is used to show a speaker's weak commitment to the communicated content due to lack of faith. This epistemic modal verb is paraphrased as "it is possible that ...". Could conveys a remote assessment of the possibility. Epistemic could is usually used to pre-assert the possibility of an event at the moment of speaking. In example [44], the speaker expresses the probability of a certain proposition in the part of the utterance with could, but the second part of the utterance denies the probability just mentioned or gives a counterargument: 
(44) "Who in hell knows? The bodies are still warm. Give us a break. There's precious little evidence right now. With no witnesses, no prints, no screwups, it'll take time to piece this thing together. Could be the same man, I don't know. It's too early."

"Surely you have a gut feeling," the President said.

Voyles paused and glanced at the windows. "Could be the same guy, but he must be superman. Probably two or three, but regardless, they had to have a lot of help. Someone fed them a lot of information" (Grisham, 1992: 138).

Epistemic could indicates that the speaker hesitates in the uttered:

(45) "Champagne breakfast!" said Madeline. "It's all in the way you package it. We'll have champagne and orange juice. Half a glass each! Over two hours. Jane? Are you in?"

"I guess I could have a sip," said Jane. "I'm a cheap drunk" (Moriarty, 2014: 38).

Could can express probabilities in the present $(46,47)$ and past $(48)$ tenses.

(46) It could happen - possibly, unlikely, but there is precedent - that the river might sweep my body all the way to the ocean (Flynn, 2012: 240).

(47) In all the days I'd worked at Runway, I'd never met a single person who dared to badmouth Miranda so boldly. Was she serious? Could she be baiting me? (Weisberger, 2003: 148)

(48) Graeme: I think you're barking up the wrong tree there. I don't see how an ill-advised champagne breakfast could have led to murder and mayhem, do you? (Moriarty, 2014: 39)

As the distributive analysis shows, could is often used with the epistemic adverbs maybe, perhaps, possibly and the epistemic phrases I guess, I assume. Thus, in the following cases, epistemic adverbs give the modal verb could epistemic meaning:

(49) Maybe she could go back to sleep (Moriarty, 2014: 57).

(50) Maybe it was going to be a really good year for them. Perhaps she could stay. It was always such a glorious relief when she allowed herself to believe she could stay (Moriarty, 2014: 61).

Questions with could question a particular proposition, especially if could is repeated in several consecutive questions:

(51) How could that be? How could you eat only that? A mouse would starve already on that (Selby, 1999: 40).

\section{Modal verbs with a medium degree of uncertainty}

Huddleston R. and Pullum G. note that "the deontic component in meaning is the background for epistemic should and ought to" (Huddleston, Pullum, 2002: 187). Scientists note that for should and ought to deontic meaning has an advantage over epistemic. Epistemic should conveys the modality of medium strength. Epistemic should, as a rule, is subjective and indicates a cautious assumption or assessment of the probability of the proposition:

(52) "Perhaps we should talk immediately," he said.

"Perhaps. But I'll call you in the morning" (Grisham, 1992: 218).

Thus, in [52] should conveys a deontic necessity, but the epistemic adverb perhaps and the context of use give should an epistemic meaning. Epistemic should is also often used with maybe.

Shouldn't expresses the speaker's opinion about the incorrectness or undesirability of the proposition. In [53] "It shouldn't" is paraphrased as "It's unlikely":

(53) He was right. The family tree was due tomorrow. She'd had it in her head that it was due the same Friday as her dad's birthday dinner, but then Dad's dinner had been moved until a week later because her brother was going away with a new girlfriend. It was all bloody Dane's 
fault. No. It was her fault. She only had one child. She had a diary. It shouldn't be that hard. They'd have to do it now. Right now (Moriarty, 2014: 150).

It should be noted that should and ought to acquire an epistemic meaning before existential propositions with to be:

(54) I didn't give you the benefit of the doubt: that no matter how much you and I blunder, you always love me and want me to be happy. And that should be enough for any girl, right? (Flynn, 2012: 137)

(55) There ought to be some wild berries (Atwood, 2004: 136).

\section{Conclusions}

Thus, in this article the following modal verbs that convey epistemic modality were analyzed - must, have to/have got to, will, would, may, might, can, could, should and ought to. These epistemic modal verbs convey varying degrees of confidence. Must expresses judgments that border on confidence. Mustn't does not have an epistemic meaning, as it expresses a deontic modality associated with prohibition, order. Can't occupies the epistemic lacuna for mustn't, indicating a lack of probability that borders on confidence. Can, in turn, mainly has no epistemic meaning, but only deontic and dynamic. Epistemic have to is close in strength to must, but it is much less common in discourse. Have got to expresses affective epistemic modality.

We share the opinion of linguists (Palmer F., Wekker H.), who believe that will is a tense indicator and futurality token, and utterances with will are factual statements, not judgments. However, will in conditional sentences indicates a high probability that something will happen, so such will will have a component of epistemic meaning and it is equivalent to must. Hypothetical and tentative would is also epistemic. If we compare the hypothetical would with the hypothetical will, then would in this case expresses a lower probability than will.

Epistemic should and ought to convey a medium-strength modality and make cautious assumptions. For epistemic should and ought to deontic meaning is the background. It should be noted that should and ought to often acquire epistemic meaning before existential propositions with to be.

Epistemic may and could express a weak degree of confidence and indicate hesitation in what is said. With may, the speaker expresses a true or false assumption, which is much weaker than the assumption with must. Epistemic may indicates a lack of speaker's confidence in the uttered proposition, a weak commitment to the content of what he says, no responsibility for the content of the utterance. Epistemic may in questions is rare, and maybe, which is derived from may be (that), is more common. May and may not can be used simultaneously in the same utterance, indicating the indecision of the speaker. Epistemic could expresses the speaker's weak commitment to the content communicated due to lack of faith.

We support the opinion of Coates J. that in everyday colloquial language might is used more often than may, and does not convey such an uncertain meaning as may. This is confirmed, in our opinion, by the distributive analysis of statements - may and could statements are often followed by contradictory statements, which refute the proposition mentioned in the first part of the statement or in the previous statement. Utterances with such a structure with might are less common.

Hypothetical weak use is common for could and would. Hypothetical use indicates a certain probability under some conditions. Would exhibits a greater degree of confidence than could. Could is a marker of "unactualized probability", so it has a lower degree of confidence. 
Hypothetical weak use of could and would adds a component of uncertainty and tentativeness in the meaning of utterances.

If we consider the degree of modality of the considered epistemic modal verbs, we can note that must, might, may have a high degree of epistemic modality, because they can convey epistemic meaning independently, without forming harmonious phrases with other epistemic words. Whereas, should, ought to, could, can't, have to, will and would have a low degree of epistemic modality, because they are mostly found in harmonious phrases with other epistemic words. The deontic meaning in should, ought to, could, can't, have to is more pronounced than epistemic, so these modal verbs are often modified with epistemic words and expressions. For will and would the defining feature is futurality, but they are epistemic if they are modified by other epistemic words or if they are hypothetical.

If we place these epistemic modal verbs on the probability scale of Renooij S. and Witteman C., then must, have to, will and would modified with epistemic words and hypothetic will belong to "probable" (85\%) part of the scale, should, ought to, and hypothetic would belong to "fifty-fifty" (50\%) part of the scale, might, may, could belong to "uncertain" (25\%) part of the scale, might not, may not, could not, would not, should not belong to "improbable" (15\%) part of the scale, can't, will not belong to "impossible" $(0 \%)$ part of the scale.

Epistemic words and phrases that occur with modal verbs in modal forms and combinations of harmonic and disharmonious type, give modal verbs a certain strength of modality and direction. Thus, in our opinion, epistemic phrases such as I guess, I suppose, I think, which denote thinking, soften the confidence of statements with strong modal verbs must, have to and reduce the uncertainty of weak modal verbs might, may, could. This can be explained by the fact that epistemic phrases denoting thinking are different from the confident $I$ know and the insecure I don't know. This phenomenon is explained by the following logical formulas:

$$
\begin{aligned}
\operatorname{MVs}(p) & =\mathrm{C}(\mathrm{p}), \text { but EP MVs }(\mathrm{p})=\mathrm{C}^{\prime}(\mathrm{p}), \\
\operatorname{MVw}(\mathrm{p}) & =\mathrm{U}(\mathrm{p}), \text { but EP MVw }(\mathrm{p})=\mathrm{C}^{\prime}(\mathrm{p}),
\end{aligned}
$$

where MVs - strong modal verb, $\mathrm{p}$ - proposition, $\mathrm{C}$ - confidence, EP - epistemic phrase, $\mathrm{C}^{\prime}$ - reduced confidence, $\mathrm{MVw}$ - weak modal verb, $\mathrm{U}$ - uncertainty. The mentioned epistemic phrases increase the degree of epistemic modality for modal verbs with a strong background deontic meaning should, ought to, could, can't and give epistemic meaning to the futural will and would. Also, epistemic phrases and words can give modal verbs a certain direction in terms of probability. Thus, in the statement "It might, I hope so", the second part gives might a direction to certainty, and in the case of the statement "I doubt it could", the epistemic doubt gives could a direction to uncertainty.

\section{References}

Atwood, M. (2004). Oryx and Crake. New York: Anchor Books.

Berry, R. N. (1960). An extension of Foley's 'Expression of Certainty'. Champaign: University of Illinois Press.

Coates, J. (1983). The Semantics of the Modal Auxiliaries. London: Croom Helm.

Collins, P. (2009). Modals and Quasi-modals in English. Amsterdam-New York: Rodopi.

Collins, S. (2008). The Hunger Games. New York: Scholastic Press.

Flynn, G. (2012). Gone Girl. London: Weidenfeld \& Nicolson.

Grisham, J. (1992). Pelican Brief. New York: Dell.

Hawkins, P. (2015). The Girl on the Train. London: Transworld Publishers.

Hornby, N. (1995). High Fidelity. London: Victor Gollancz Ltd. 
Huddleston, R., Pullum, G. K. (2002). The Cambridge grammar of the English language. Cambridge: Cambridge University Press.

King, S. (2016). The Running Man. New York: Pocket Books.

Meyer, S. (2005). Twilight. New York Boston: Little, Brown and Company.

Moriarty, L. (2014). Big Little Lies. New York: G. P. Putnam's Sons.

Palmer, F. (1990). Modality and the English modals, 2nd edn. London: Longman.

probabilistic information with words and numbers. New York: Elsevier.

Renooij, S., Witteman, C. (1999). Talking probabilities: communicating

Selby, H. (1999). Requiem for a Dream. Cambridge: Da Capo Press.

Teigen, K. H., Brun, W. (1995). Yes, but it is uncertain: Direction and communicative intention of verbal probabilistic terms. Gent: Elsevier.

Tyler, A. (2004). The Amateur Wedding. London: Vintage.

Weisberger, L. (2003). The Devil Wears Prada. New York: Doubleday.

Wekker, H. (1976). The Expression of Future Time in Contemporary British English: an Investigation into the Syntax and Semantics of Five Verbal Constructions Expressing Futurity. Amsterdam: North-Holland Pub.

Wesson, C., Pulford, B. (2009). Verbal expressions of confidence and doubt. Thousand Oaks: Sage Journals. 